\title{
Seasonal and inter-annual temperature variability in the bottom waters over the western Black Sea shelf
}

\author{
G. I. Shapiro ${ }^{1,2}$, F. Wobus ${ }^{1}$, and D. L. Aleynik ${ }^{2,3}$ \\ ${ }^{1}$ School of Marine Science and Engineering, University of Plymouth, Plymouth, UK \\ ${ }^{2}$ P. P. Shirshov Institute of Oceanology, Moscow, Russia \\ ${ }^{3}$ Scottish Association of Marine Science, Oban, UK \\ Received: 28 December 2010 - Published in Ocean Sci. Discuss.: 2 February 2011 \\ Revised: 17 August 2011 - Accepted: 9 September 2011 - Published: 22 September 2011
}

\begin{abstract}
Long-term changes in the state of the Bottom Shelf Water (BSW) on the Western shelf of the Black Sea are assessed using analysis of intra-seasonal and inter-annual temperature variations. For the purpose of this study the BSW is defined as such shelf water mass between the seabed and the upper mixed layer (bounded by the $\sigma_{\theta}=14.2$ isopycnal) which has limited ability to mix vertically with oxygenrich surface waters during the warm season due to formation of a seasonal pycnocline. A long-term time series of temperature anomalies in the BSW is constructed from in-situ observations taken over the 2 nd half of the 20th century. The BSW is shown to occupy nearly half of the shelf area during the summer stratification period (May-November).The results reveal a warm phase in the 1960s/70s, followed by a cold phase between 1985 and 1995 and a further warming after 1995. The transition between the warm and cold periods coincides with a regime shift in the Black Sea ecosystem. While it was confirmed that the memory of winter convection is well preserved over the following months in the deep sea, the signal of winter cooling in the BSW significantly reduces during the warm season. The potential of the BSW to ventilate horizontally during the warm season with the deep-sea waters is assessed using isopycnic analysis of temperature variations. It is shown that temperature in the BSW is stronger correlated with the temperature of Cold Intermediate Waters (CIW) in the deep sea than with the severity of the previous winters, thus indicating that the isopycnal exchanges with the deep sea are more important for interannual/inter-decadal variability of the BSW on the western Black Sea shelf than effects of winter convection on the shelf itself.
\end{abstract}

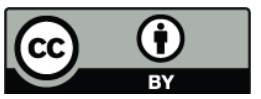

Correspondence to: G. I. Shapiro (gshapiro@plymouth.ac.uk)

\section{Introduction}

The coastal and shelf zones of the Black Sea are of immense economic significance, they contain biologically productive, diverse ecosystems that provide a vital habitat for many commercial and endangered species. Until mid-1980s, it supported fisheries almost five times richer than those of the neighbouring Mediterranean. In the end of the 20th century the Black Sea has experienced the worst environmental degradation of all of the world's major seas (Mee et al., 2005).

The environmental crisis and subsequent dramatic changes in the Black Sea's ecosystem are a direct effect of both natural and anthropogenic causes (Salihoglu, 2000). At the same time, significant changes in the physical environment have been reported (McQuatters-Gollop et al., 2008; Oğuz, 2005). There is growing understanding that changes in the Black Sea ecosystem are stronger influenced by climate change than previously thought (Daskalov, 2003; Oğuz, 2005).

The influence of changes in the physical environment on the ecosystem cannot be properly assessed without accurate analysis of the variability of the marine physical sub-system in its own right. The studies of long-term (interannual or interdecadal) variations of physical parameters of the Black Sea are sparse, they are commonly restricted by analysis of the deep sea only, and usually deal with either sea surface temperature (Oğuz, 2005; McQuatters-Gollop et al., 2008) or temperature variations in the Cold Intermediate Water (CIW) of the deep basin (Ivanov et al., 2000; Belokopytov, 1998).

The link between the physical and biochemical parameters of the Black Sea has been established, in particular the connection between water density and vertical profiles of chemical parameters (Vinogradov and Nalbandov, 1990; Murray et al., 1995; Yakushev et al., 2005). The oxycline and the chemocline occur at the same depth intervals as the

Published by Copernicus Publications on behalf of the European Geosciences Union. 
halocline, because of similarity in the mechanisms of vertical exchanges (Özsoy and Ünlüata, 1997). Supply of oxygen to the near-bottom waters, which is controlled by physical processes, is crucial for functioning of the benthic ecosystem (Yakushev et al., 2005). Habitats with normal levels of oxygen occur in the narrow coast zone from the shore to 7 $10 \mathrm{~m}$ and in the deeper shelf zone from $40 \mathrm{~m}$ to the onset of permanently anoxic conditions at around $130 \mathrm{~m}$ (Zaitsev, 2006). While coastal areas are free from hydrogen sulphide, concentrations increase in the deeper parts of the shelf due to the restricted ventilation under the thermocline (Zaitsev et al., 2002).

The focus of this paper is on the long-term variation in the temperature of Bottom Shelf Water (BSW) on the productive Western shelf. For the purpose of this study the BSW is defined as such shelf water mass between the seabed and the upper mixed layer which has limited ability to mix vertically with oxygen-rich surface waters during the warm season (May-November) due to the formation of a seasonal pycnocline. This water mass has an arguably stronger influence on the deeper benthic communities of the outer shelf (depth range $40-130 \mathrm{~m}$ ) than parameters at the sea surface. As we show later in Sect. 3, the areas occupied by the deeper shelf ecosystem coincide well with the spread of the BSW and hence knowledge of temporal variations in the physical state of BSW could help understand the decline and recovery cycles of the benthic ecosystem.

During the winter months the BSW on the extensive Black Sea shelf is subject to strong convective mixing with the surface waters and hence an intensive ventilation of the bottom waters occurs during the cold season. On the contrary, the heating of the surface waters during the warm season (here defined as May to November) weakens the link between the surface and bottom waters due to formation of a strong vertical density gradient that hampers vertical mixing and the bottom waters become isolated from the surface. It has been suggested that the strengthening of the seasonal pycnocline in summer is associated with the reduction of the oxygen supply to the bottom waters (Keondzhyan et al., 1990, p. 18).

Suppression of vertical mixing does not mean that the BSW is completely arrested - they can still be involved in horizontal (more precisely - isopycnal) exchanges with deep sea waters. There is a number of ways in which horizontal exchanges contribute to communication between the shelf and the deep Black Sea, including transport by Rim Current meanders, mesoscale eddies, shelf edge cascading etc. (see e.g. Blatov et al., 1984; Gawarkiewicz et al., 1999). Horizontal shelf-deep sea exchanges are considered as one of the mechanism of formation of the Cold Intermediate Water (CIW) in the deep Black Sea (e.g. Sorokin, 2002; Stanev et al., 2004). Shelf-deep sea interactions are known to have impact on the sea surface temperature over the shelf (Ginzburg et al., 2002), spatial distribution of chlorophyll (Oğuz et al., 2002; Shapiro et al., 2010b) and the state of the Black Sea ecosystem (Sur et al., 1996), however the strength of these

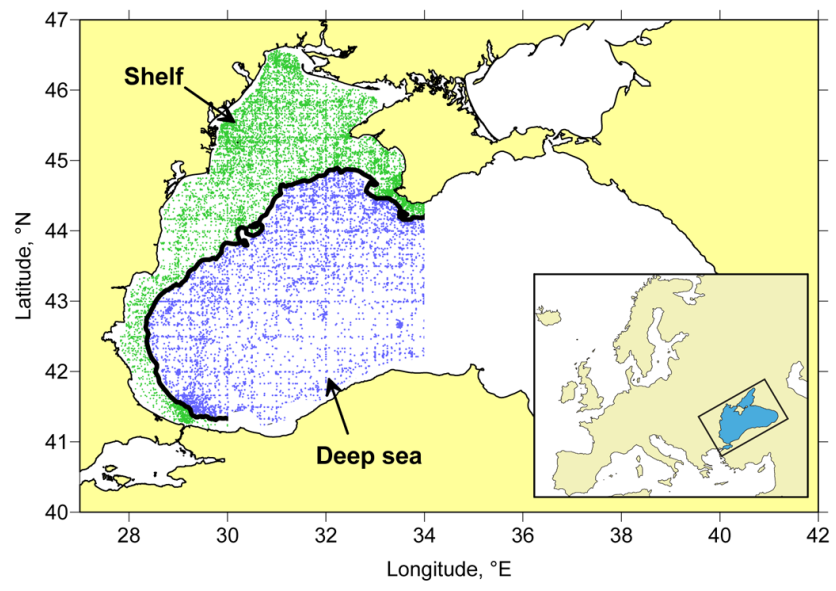

Fig. 1. Location map of the Black Sea and the boundaries of the shelf and deep sea compartments (separated by the $150 \mathrm{~m}$ isobath shown in bold). Also shown are the locations of stations in the combined WOD + ROM + MHI data set used for calculation of interannual variability for 1950-2004 in the shelf compartment (green, 27016 stations) and the deep sea compartment (blue, 11710 stations).

exchanges was difficult to quantify and this issue has motivated the present study.

In this paper we use historic data sets to identify intraseasonal, inter-annual and inter-decadal variability in the temperature of the BSW over the western Black Sea shelf. We also analyse the correlation of these changes with other physical parameters of the shelf and deep-sea waters, and the overlying atmosphere. Correlation between shelf and deep sea waters are used to examine potential role of lateral exchanges in variability of parameters and the ventilation of the BSW on the extensive western Black Sea shelf. We use temperature as an indicator for general physical conditions in the BSW. The physical reason for this is that inter-annual variations in the near-bottom temperature are directly related with the variations in the volume of cold waters (Ivanov et al., 2000) which are formed on the shelf and then exported into the deep sea. The other reason is that the variations in the strength of the thermocline above the BSW reflect variations in the vertical fluxes of heat and dissolved matter including oxygen (Vinogradov and Nalbandov, 1990; Yakushev et al., 2005).

\section{Data and methods}

\subsection{Geographical compartments and data sets}

The area for this study includes the western part of Black Sea (both shelf and the deep sea) as shown in Fig. 1. The area is subdivided into 2 compartments: the western shelf and the western deep sea. The compartments are defined in the western Black Sea over $41.05^{\circ} \mathrm{N}$ to $47^{\circ} \mathrm{N}$ and $27^{\circ} \mathrm{E}$ to $34^{\circ} \mathrm{E}$. The shelf boundary is considered to be the $150 \mathrm{~m}$ 
depth contour which forms the lower limit of the deep benthic ecosystem on the shelf (Zaitsev, 2006). The bathymetry was taken from ETOPO2v2 (NGDC, 2006). The sources of data are a combination of the temperature data subset from the World Ocean Database 2001 (Stephens et al., 2002), for the period 1910-2000, which includes 18314 individual stations, the data set obtained from the Romanian Marine Research Institute (RMRI), which includes 2362 stations covering the period 1963-2004 and a further 35677 stations (for 1950-2001) from the Black Sea Digital Atlas of the Marine Hydrophysical Institute (Sevastopol, Ukraine) (Suvorov et al., 2004). Individual data sets are hereafter called "WOD", "ROM" and "MHI", respectively. In order to eliminate erroneous data points, the WOD + ROM data set was subject to a quality control using a two-step procedure as in Stephens et al. (2002) and Shapiro et al. (2010a), which is briefly outlined below. The data were subdivided geographically into $0.25^{\circ}$ squares. Then the approximate values of the "firstguess" (i.e. before removal of the outliers) monthly mean states and standard deviations were calculated for 12 calendar months and all $0.25^{\circ}$ degree squares at 26 standard hydrographic depth levels. Both monthly mean and standard deviation were calculated using all data within the cell. Then, the outliers, i.e. the data points with more than 6 standard deviations away from the mean, were removed from the data base and the process was repeated 3 times, which resulted in removal of 2797 of stations from the WOD data set. Data from the MHI data set was quality controlled by the originators (Suvorov et al., 2004).

The locations of stations used for the calculations of temperature variations from the combined WOD + ROM + MHI dataset are shown in Fig. 1.

\subsection{Climatology and inter-annual variability}

In order to calculate deviations from climate, the mean (climatic) values were calculated first. For consistency with the previous study (Shapiro et al., 2010a) we calculate the monthly climate averages for the period 1910-2000 using the WOD + ROM data set. Climatic averages are calculated using the adaptive grid method as in Lozier et al. (1995) and Shapiro et al. (2010a) where further details can be found. The idea of this method is to use smaller grid sizes where the data is abundant and larger grids in the areas of sparse data. The Black Sea is split into $0.25^{\circ} \times 0.25^{\circ}$ squares, and the averages at each grid point and each depth level are calculated using a two-scale weighting function (Willis et al., 2004):

$C(r)=\theta\left(\frac{r}{r_{s}}\right) \cdot \exp \left[-\frac{r^{2}}{r_{d}}\right]$

where $\theta(x)=1$ at $x \leq 1$ and $\theta(x)=0$ at $x>1 ; r$ is the distance between the sampling station and the grid node; and $r_{s}$ and $r_{d}$ are the coefficients. Larger values of $r_{s}$ and $r_{d}$ result in better statistical accuracy but lower spatial resolution and vice versa. Parameters $r_{s}=100 \mathrm{~km}$ and $r_{d}=25 \mathrm{~km}$ are selected as in Shapiro et al. (2010a) to provide a balance between horizontal resolution and statistical accuracy of the calculated mean values. The resulting climatology is close to that by Boyer et al. (2005) and Suvorov et al. (2004). For each grid point we compute the climatological density profile which allows to convert $\mathrm{z}$-coordinates into $\sigma_{\theta}$-coordinates.

The next step is to calculate inter-annual and inter decadal variability of parameters of interest. The amount of observational data is often insufficient to produce statistically robust assessment of inter-annual variability based on the absolute values, so that the data are often aggregated in time into large (for example decadal) blocks, however such method greatly reduces the temporal resolution of the analysis (see e.g. Shokurova et al., 2004). In line with recent climate studies of the global ocean (e.g. Levitus et al., 2009) and in contrast to many previous studies of inter-annual variability in the Black Sea, e.g. Blatov et al. (1984), Belokopytov (1998), Shokurova et al. (2004), Oğuz (2005) and references therein, we do not use the absolute temperatures as indicators of temporal changes, instead we use the temperature anomalies (i.e. deviations from monthly climatic averages). Hansen and Lebedeff (1987) have shown that the use of anomalies instead of absolute values has a significant advantage as they are stronger correlated spatially over large areas than the absolute temperatures.

The large correlation radius allows aggregating observational data over extended areas of the Black Sea and avoids the bias caused by spatial inhomogeneity of sampling sites. Reduction of such bias can be illustrated by a simple example. Assume that there were two identical years with the temperature distribution exactly equal to the climatic values. Assume further that in one year most measurements were carried out in the Northern (typically colder) area of the sea and in the other year the data were collected in the Southern (warmer) area. The method based on absolute values would provide a spurious warming trend, whilst the anomalies would be zero in all cases, correctly showing zero trend. The method of anomalies has been used recently in a number of climate studies (e.g. Jones and Mann, 2004; Willis et al., 2004; Boyer et al., 2007; Levitus et al., 2009).

In order to calculate deviations of individual observations from climatic values, the gridded climatic values are spatially and temporally interpolated to the location and the date and time of the actual measurements. Temporal interpolation to a specific date uses monthly climatic averages, which are assumed to be centred at the middle of the month, from the nearby grid points. Both profiles (measured and climatic) are interpolated in the vertical in $\sigma_{\theta}$-coordinates to density levels in $0.1 \mathrm{~kg} \mathrm{~m}^{-3}$ intervals. For stations where matching density levels are present in both actual $T\left(x, y, \sigma_{\theta}, t\right)$ and climatic $T_{\text {clim }}\left(x, y, \sigma_{\theta}, t\right)$ profiles the temperature anomalies $\left(T_{\mathrm{an}}\right)$ are calculated at each density level $\left(\sigma_{\theta}\right)$ as:

$T_{\text {an }}\left(x, y, \sigma_{\theta}, t\right)=T\left(x, y, \sigma_{\theta}, t\right)-T_{\operatorname{clim}}\left(x, y, \sigma_{\theta}, t\right)$

where $t$ is the time of observation. 
The anomalies are aggregated into two seasonal bins (cold period ("winter"): December to April, warm period ("summer"): May to November). Combination of anomalies from different months within a season is routinely used in climate studies as it increases the number of stations used in the analysis and improves statistical significance of the results, (e.g. Altman and Simonov, 1991; Belokopytov, 1998; Oğuz et al., 2006). Using the property of anomalies to be highly spatially correlated (Hansen and Lebedeff, 1987) they are further aggregated spatially over each geographical compartment, either the western shelf or the western deep sea. The final step is to aggregate anomalies in the vertical within the BSW, so that the number of sampling points representing the BSW is significantly greater than the number of stations, hence further enhancing statistical significance of the results.

In order to estimate statistical uncertainty related to combining data collected in different months of the warm season, the intra-seasonal (i.e. month-to-month) variability is assessed using temporally and spatially averaged data for each calendar month and then compared to inter-annual variability of the same parameter. Such uncertainty might have occurred due to non-identical temporal distribution of samples over the warm season in different years. For example if in one year there were more measurements during the "colder" months than in another year, a spurious inter-annual variability may have been recorded. Such spurious variability would have been likely to occur if the intra-seasonal variability had been greater or comparable with the inter-annual changes. Fortunately, calculations show that the intra-seasonal variability during the months May to November (measured as standard deviation from the mean) is significantly smaller than the inter-annual variability (see Sect. 3.1), hence justifying the method of combining the data over the period May to November. Despite the improvement in statistical accuracy due to use of the method of anomalies and aggregating data into seasons and within the BSW, the amount of data for the period 1910-1949 is still insufficient to produce reliable time series of inter-annual variability, the results are noisy and they are not reported here. For calculation of anomalies for the time period 1950-2004 we use the combined WOD + ROM + MHI set containing total of 38726 stations.

The vertical extent of the bottom waters on the shelf can be defined by a number of ways: for example by setting a specific height above bottom or choosing a specific temperature/salinity/density level. For instance, the Cold Intermediate Layer (CIL) in the deep Black Sea is traditionally defined by the $8^{\circ} \mathrm{C}$ isotherms (e.g. Blatov et al., 1984) or at its upper bounds by the isopycnic levels $\sigma_{\theta}=14.2 \mathrm{~kg} \mathrm{~m}^{-3}$ (e.g. Ivanov et al., 2000, 2001). For practical purposes these two definitions are effectively the same, as can be seen in Fig. 2. In this study we use the latter definition for the upper boundary of the BSW.

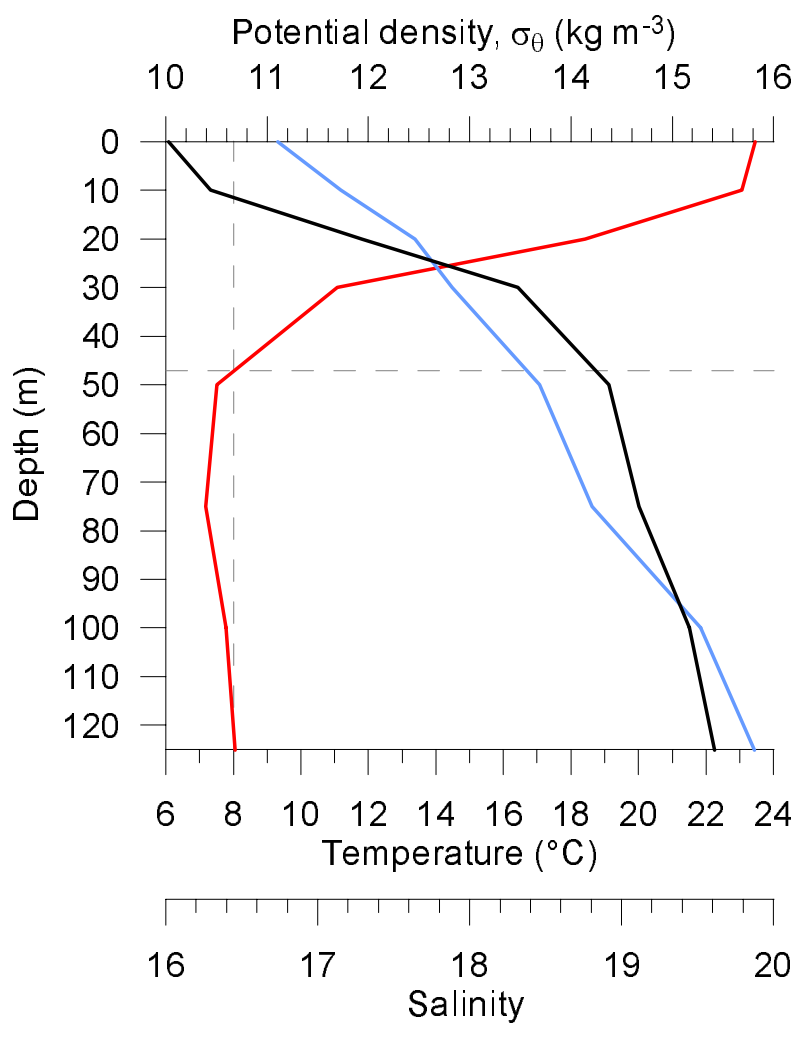

Fig. 2. A typical climatic profile of temperature (red), salinity (blue) and potential density (black) at the outer shelf $\left(44.50^{\circ} \mathrm{N}, 31.00^{\circ} \mathrm{E}\right)$ in August. The separation between the homogenous layer of Bottom Shelf Waters (BSW) and the upper thermocline occurs at approximately $47 \mathrm{~m}\left(8^{\circ} \mathrm{C}\right.$ isotherm), which coincides with the density level of $\sigma_{\theta}=14.25 \mathrm{~kg} \mathrm{~m}^{-3}$.

\section{Results}

\subsection{Climate and intra-seasonal variations}

Analysis of climatic temperature profiles reveals that the water column during the winter convection period is well mixed on most parts of the shelf and therefore does not allow a meaningful identification of the pycnocline. Further analysis is therefore restricted to the warm season (defined here as May-November) when the shelf waters are strongly stratified.

The topography of the isopycnal level $\sigma_{\theta}=14.2 \mathrm{~kg} \mathrm{~m}^{-3}$ is shown in Fig. 3 for the climatology in April (after the winter convection period) and October (after the summer stratification period). The spatial extent of the BSW calculated for each calendar month within the warm season using climatic temperature and salinity profiles is shown in Fig. 4. The contours show the coverage of the BSW, which is largely isolated from vertical mixing from the surface until the following winter. The potential of these areas to be ventilated by horizontal exchanges during the warm period is discussed in Sect. 4. 

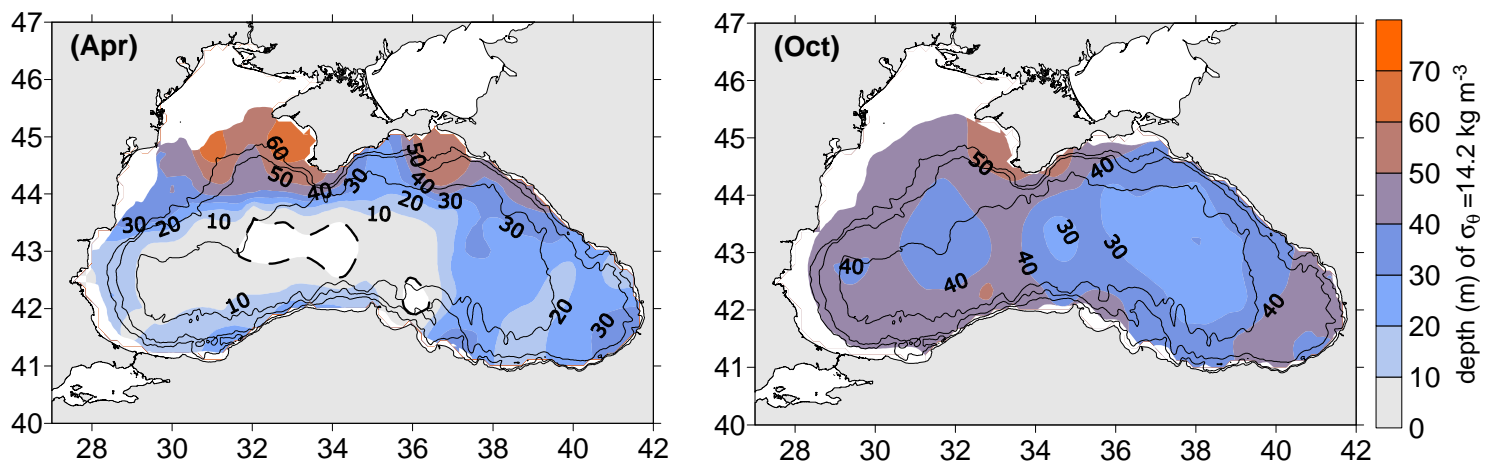

Fig. 3. Depth of climatically averaged isopycnic surface $\sigma_{\theta}=14.2 \mathrm{~kg} \mathrm{~m}^{-3}$ in April and October (shaded and numbers). The isobaths are shown at 200, 1000 and $2000 \mathrm{~m}$ levels (thin solid lines). The April plot also shows the contour of this isopycnal along the sea surface (dashed line).

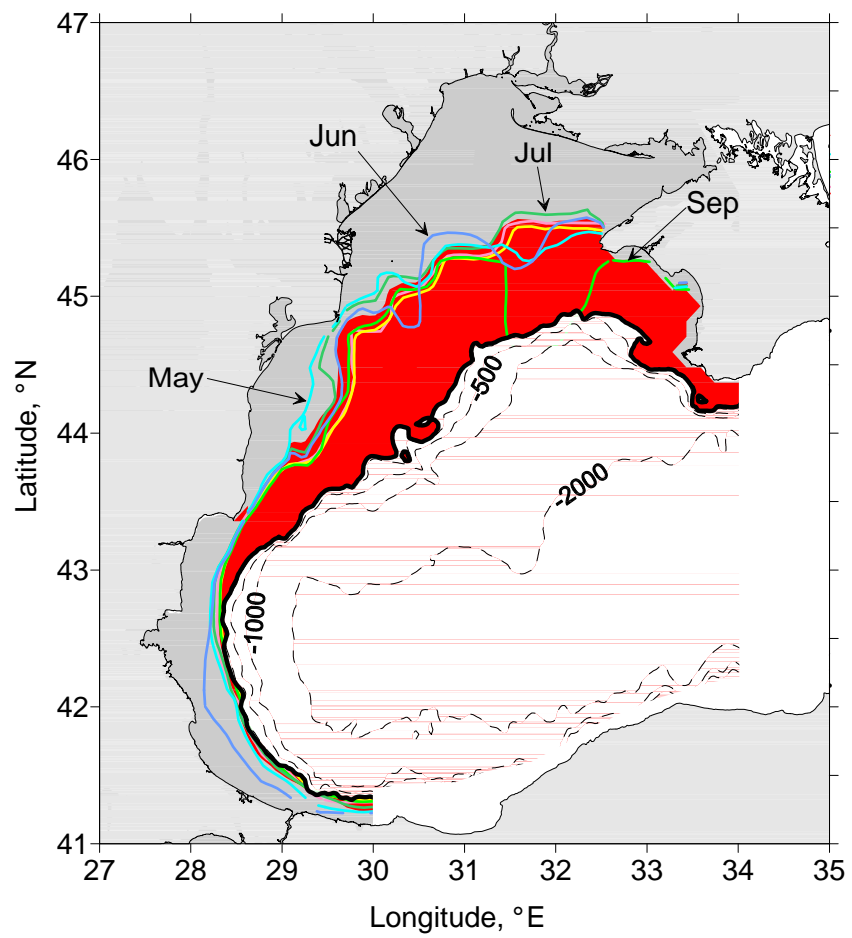

Fig. 4. Shelf area covered by BSW $\left(\sigma_{\theta} \geq 14.2 \mathrm{~kg} \mathrm{~m}^{-3}\right)$ for the individual months from May to November. The extent in August is shaded in red, while the slight deviations in other months are shown by super-imposed contour lines, several of which are individually labelled. The bold line is the shelf boundary along the $150 \mathrm{~m}$ isobath, dashed lines are isobaths at 200, 500, 1000 and $2000 \mathrm{~m}$.

Figure 5 shows that the area occupied by the BSW is fairly constant during May-November at around $38 \times 10^{3} \mathrm{~km}^{2}$, which is $45 \%$ of the total shelf area, which occupies $83300 \mathrm{~km}^{2}$ from the coast to the depth of $150 \mathrm{~m}$. The area of "locked" near-bottom waters varies from $30300 \mathrm{~km}^{2}$ in September to $40500 \mathrm{~km}^{2}$ in June. The volume of this water body varies from $900 \mathrm{~km}^{3}$ in September to $1400 \mathrm{~km}^{3}$ in June (the total volume of the shelf compartment is $4300 \mathrm{~km}^{3}$ ). Figure 5 also shows the intra-seasonal variability of the depth of the upper boundary of the BSW as identified by the isopycnal at $\sigma_{\theta}=14.2 \mathrm{~kg} \mathrm{~m}^{-3}$, which gives an average depth of $46 \pm 4 \mathrm{~m}$. This depth level approximately coincides with the upper boundary of the outer shelf benthic ecosystem which occupies the depth range from $40 \mathrm{~m}$ to the onset of permanently anoxic conditions at around $130 \mathrm{~m}$ (Zaitsev, 2006). The pycnocline deepens slightly (a few metres) during the warm season probably due to slow diapycnic mixing.

Figure 6 shows the values of spatially averaged climatic absolute temperatures within the BSW (i.e. averaged over the water body with $\sigma_{\theta} \geq 14.2 \mathrm{~kg} \mathrm{~m}^{-3}$ over the shelf up to the $150 \mathrm{~m}$ depth contour) for different months within the warm season. The intra-seasonal variability during the whole warm period shows a very small range from $7.5-8.2{ }^{\circ} \mathrm{C}$ with the mean value of $7.8^{\circ} \mathrm{C}$ (Fig. 6). With the exception of June, there is a small but systematic warming of the BSW during the warm season from $7.5^{\circ} \mathrm{C}$ in May to $8.1^{\circ} \mathrm{C}$ in November. An unexpected small increase of average temperature in June is not statistically significant due to large scatter of data for this month.

For the same months the average temperature at the upper boundary of the BSW (defined as $\sigma_{\theta}=14.2 \mathrm{~kg} \mathrm{~m}^{-3}$ ) was calculated as $8.3^{\circ} \mathrm{C}\left(\operatorname{stdev}=0.35^{\circ} \mathrm{C}\right)$ which closely coincides with the classical definition of the boundary of CIW as the $8^{\circ} \mathrm{C}$ isotherm.

\subsection{Inter-annual and inter-decadal variability}

For reasons discussed in Sect. 2, inter-annual and interdecadal variability is analysed using temperature anomalies rather than absolute values. A time series of temperature anomalies averaged spatially over the area and the vertical expanse of the BSW (from $\sigma_{\theta}=14.2 \mathrm{~kg} \mathrm{~m}^{-3}$ down to a depth of $150 \mathrm{~m}$ ) and temporally over the warm season (May-November) of each year (Fig. 7) was constructed using methodology described above in Sect. 2. 


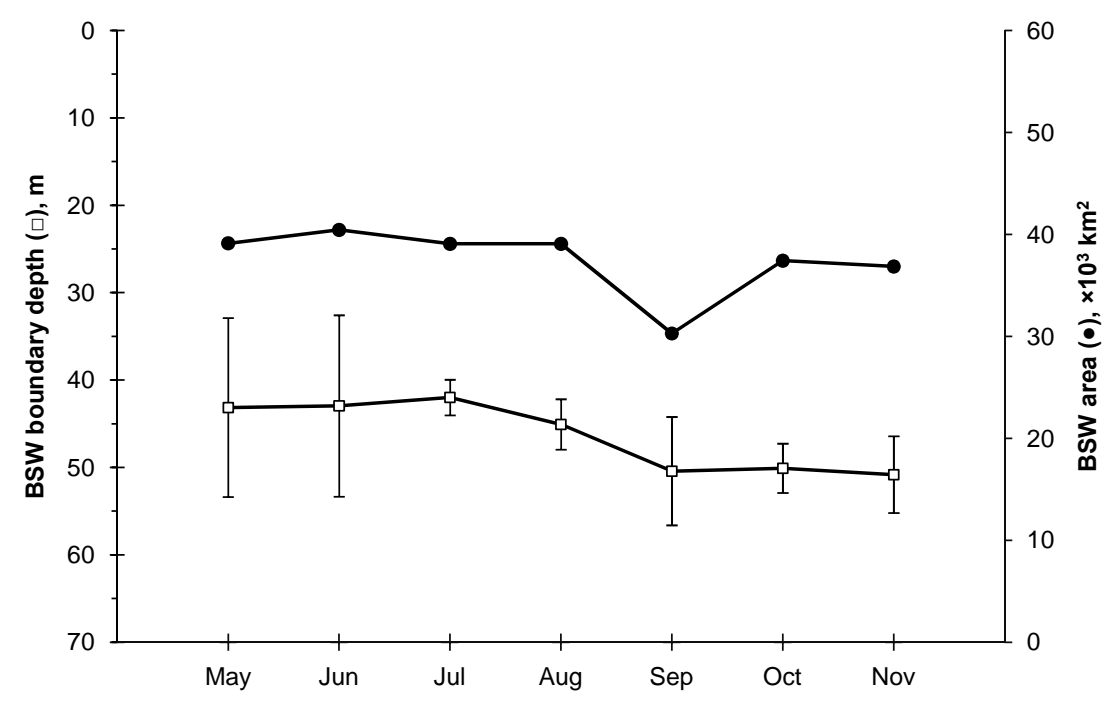

Fig. 5. Intra-seasonal variability (May-November) of the coverage (in $\times 10^{3} \mathrm{~km}^{2}$ ) of BSW (full circles) and the average depth of the isopycnal $\sigma_{\theta}=14.2 \mathrm{~kg} \mathrm{~m}^{-3}$ which represents the upper boundary of the BSW, for the same period (open squares). Error bars show 1 standard deviation.

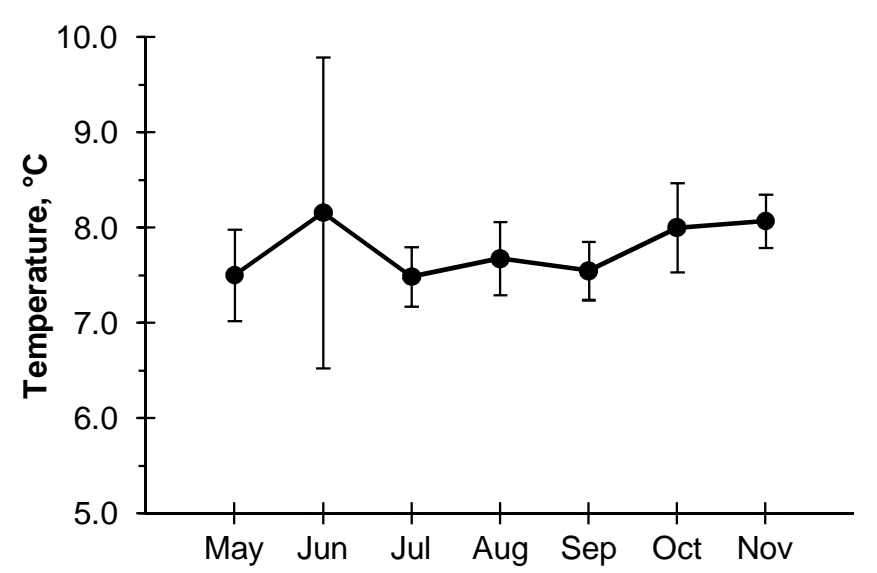

Fig. 6. Intra-seasonal variability (May-November) of absolute temperature $\left({ }^{\circ} \mathrm{C}\right)$ in the BSW. Error bars show 1 standard deviation due to variations of BSW temperature in individual nodes of the climate grid.

Figure 8 shows the distribution of stations available in different years for the calculation of temperature anomalies in the BSW during the warm period (May-November). Out of a total 27016 stations available for the shelf compartment from 1950-2001 the time series of BSW temperature anomalies (see Fig. 7) was constructed from a subset of 5568 stations (with 111336 individual samples of temperature and salinity within the BSW) because other stations either fell outside of the period of interest (May-November) or did not reach deep enough into the BSW. Large number of samples within the BSW results in small statistical uncertainties as shown by small error bars in Fig. 7.
The temperature anomalies range between $-1.16^{\circ}$ in 1996 and $+1.48^{\circ} \mathrm{C}$ in 1979 . The interdecadal variability is thus significantly greater than the than the small statistical uncertainty of less than $0.2^{\circ} \mathrm{C}$ associated with this climatic data set (Shapiro et al., 2010a). It is also much greater than the intraseasonal variability between May and November shown in Fig. 6, thus justifying temporal aggregation of temperature data in the BSW into a single seasonal value for the entire warm period of each year.

A warmer-than-average period is evident from the early 1960 s to the early 1980s followed by a colder-than-average period from the early 1980s to the early 2000s. Figure 7 clearly shows 2 warming periods when the temperature rose, one lasted from the early 1960s to the early 1970s, the other started in the mid-1990s and continued at least to the end of the data set. Despite their similarities there is an important difference between them: the first warming period (19601970 s) started from climatically "normal" condition $\left(T_{\mathrm{an}}=\right.$ 0 ), whilst the second one (1990-2000s) started from a colder than climatically averaged state $\left(T_{\mathrm{an}} \approx-0.8^{\circ} \mathrm{C}\right)$ and did not reach the climatic mean temperatures until after 2000 . These warming periods were separated by a 20 -year-long cooling period from the early 1970s to 1990s.

The parameters of the BSW are influenced by neighbouring water masses and by the meteorological conditions particularly during the winter season when intensive vertical mixing with surface waters takes place. The correlations between the inter-annual variations of the BSW temperature and other local and remote parameters are analysed using Pearson correlation coefficients. In order to preserve comparability with the previous studies (Altman and Simonov, 1991; Belokopytov, 1998) correlations with external 


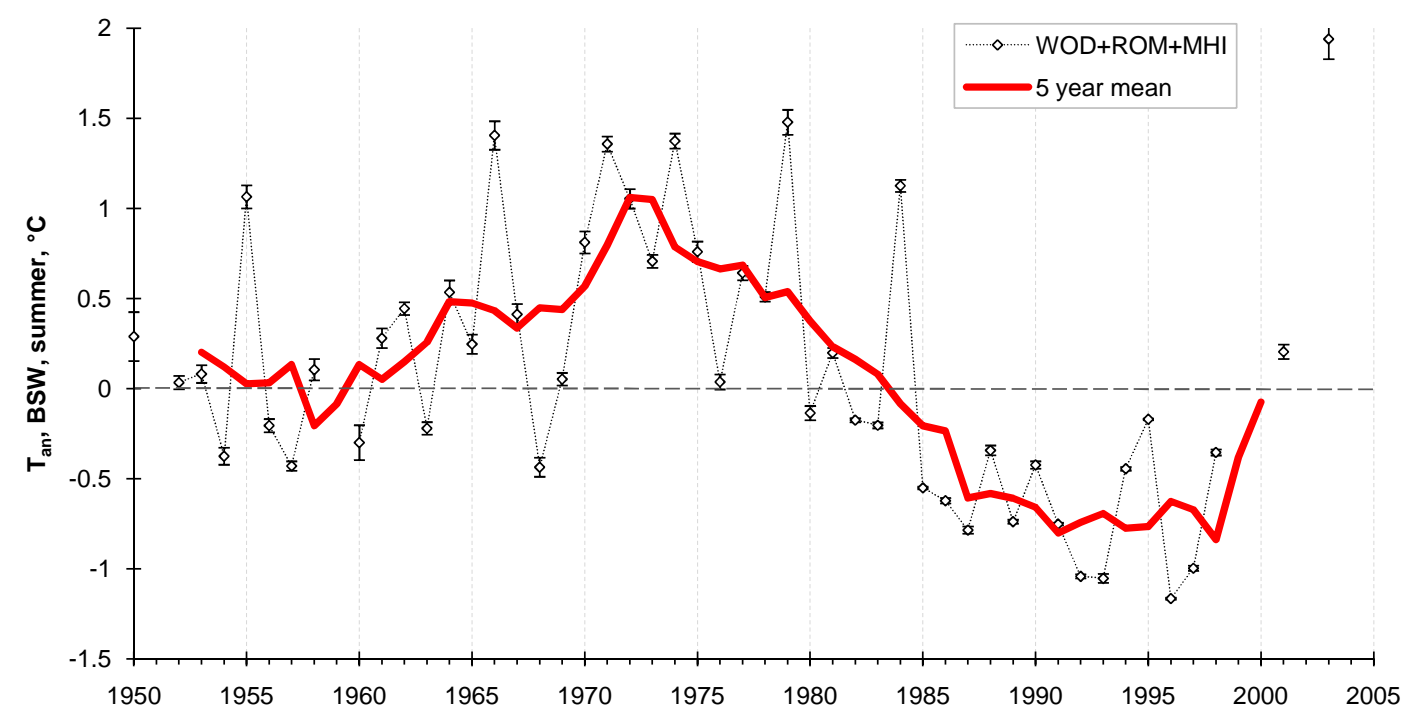

Fig. 7. Long-term time series of the temperature anomaly $\left({ }^{\circ} \mathrm{C}\right)$ of BSW calculated from the combined WOD $+\mathrm{ROM}+\mathrm{MHI}$ dataset for the warm period (May-November) in 1950-2004 (dotted line) and the 5-yr running mean (red line). Error bars show the standard error of the mean. See Fig. 8 for the number of stations available in each year.

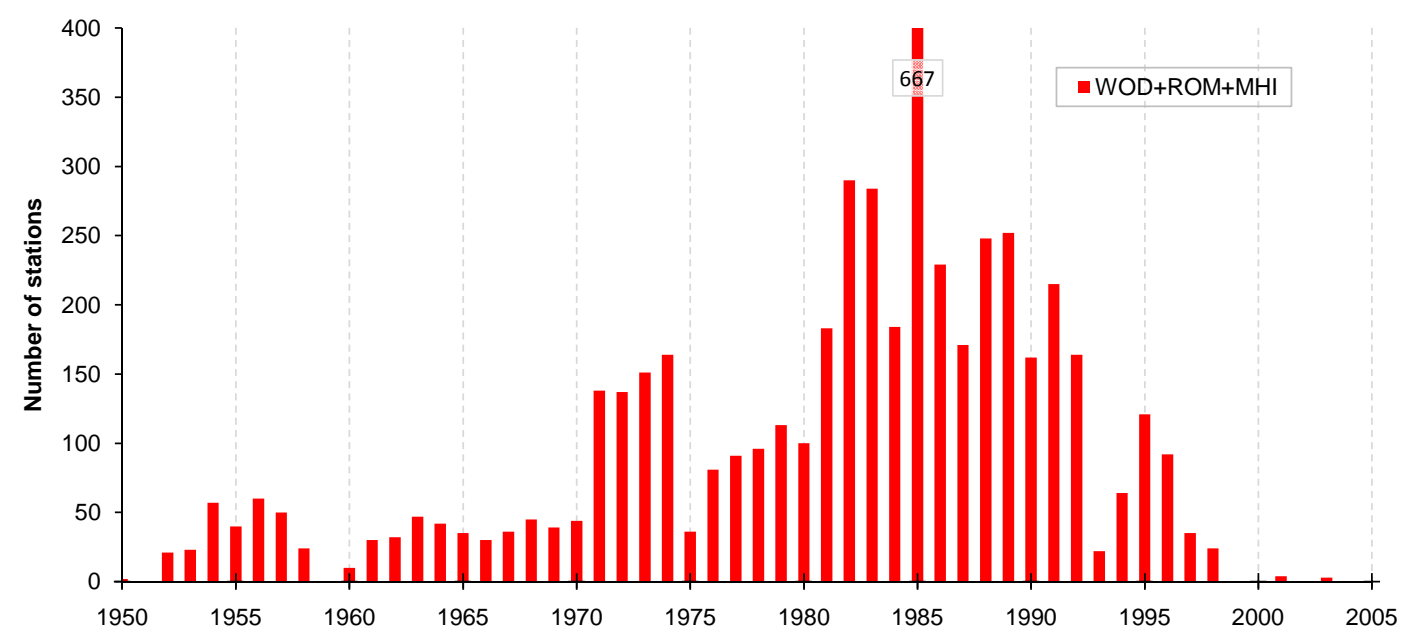

Fig. 8. Number of stations in the shelf compartment for which BSW temperature anomalies during May-November could be calculated from the combined WOD + ROM + MHI dataset.

meteorological conditions are assessed using the long-term time series of the "winter severity index" $\Sigma t_{\mathrm{a}}$ which is traditionally calculated as the sum of negative air temperatures during winter (November-April) from meteorological station at Odessa, Ochakov and Khorly along the North-Western shore of the Black Sea shelf (Fig. 9).

The effect of winter cooling is first felt at the sea surface and hence correlation between the winter sea surface temperature and the summer temperature in the BSW would show how well the effect of winter cooling is preserved in the shelf bottom waters. Interannual variability of the winter sea surface temperature of shelf waters is estimated similar to the bottom waters, i.e. by calculating temperature anomalies us- ing Eq. (2) and then aggregating them over the shelf compartment (see Fig. 1) however temporal aggregation is done over the cold period (December-April) of each year (Fig. 9). In a similar way, the inter-annual variability was calculated for the temperature of CIW (defined by the density range $\sigma_{\theta}=14.2-14.8 \mathrm{~kg} \mathrm{~m}^{-3}$, as in Ivanov et al., 1997) during the warm season (May-November) in the deep part of the western Black Sea (Fig. 10). The temperature response of surface waters in the deep sea to winter cooling is characterised by a long-term series of the winter (December-March) mean sea surface temperature averaged over the interior basin with depths greater than $1500 \mathrm{~m}$ obtained from Oğuz et al. (2006), see Fig. 10. 


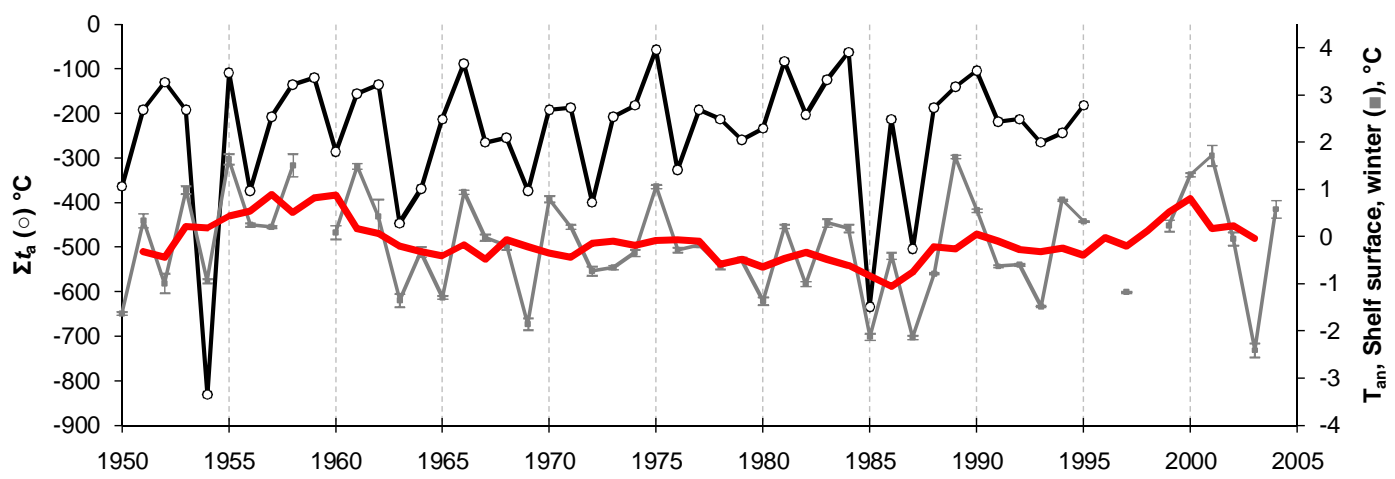

Fig. 9. Long-term time series of the winter severity index $\Sigma t_{\mathrm{a}}\left({ }^{\circ} \mathrm{C}\right)$ for the North-Western part of the Black Sea (black line + circles, redrawn from Belokopytov, 1998) and time series of the winter (December-April) temperature anomaly $\left({ }^{\circ} \mathrm{C}\right)$ of the shelf surface (grey line + squares), and the 5-yr running mean (red line). Error bars show the standard error of the mean.

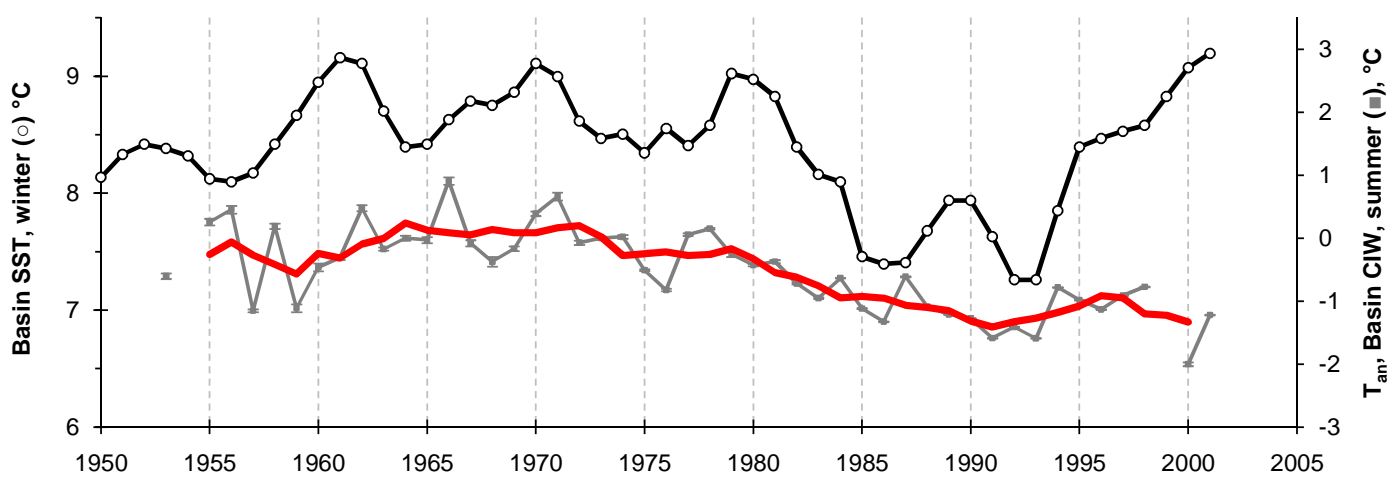

Fig. 10. Long-term time series of the mean sea surface temperature $\left({ }^{\circ} \mathrm{C}\right)$ in winter averaged over the interior basin with depths greater than $1500 \mathrm{~m}$ (thin black line + circles, redrawn from Oğuz et al., 2006) and time series of the summer (May-November) temperature anomaly $\left(T_{\mathrm{an}},{ }^{\circ} \mathrm{C}\right)$ of Cold Intermediate Water (CIW) $\left(\sigma_{\theta}=14.2-14.8 \mathrm{~kg} \mathrm{~m}^{-3}\right)$ in the deep sea compartment (grey line + squares), and the 5-yr running mean (red line). Error bars show the standard error of the mean.

Figure 11 shows the correlation between monthly values of temperature anomalies in the sea surface layer $(0-10 \mathrm{~m})$ averaged over the shelf compartment and monthly temperature anomalies of the BSW covering the months MayNovember for the period 1950-2004. The Pearson correlation is only $R=0.22$, which confirms decoupling between the surface layer and the BSW during the summer stratification period, thus justifying the concept of the BSW being "locked", i.e. isolated from the direct influence of atmospheric forcing.

Figure 12 summarises the correlations (Pearson R-values) of long-term temperature time series of the winter severity index $\Sigma t_{\mathrm{a}}$, SST of the basin interior in winter, temperature anomaly $\left(T_{\mathrm{an}}\right)$ of the shelf surface in winter, $T_{\mathrm{an}}$ of the BSW in summer and CIW in the deep sea in summer. In the next section, these correlations are used to discuss the links between various factors that influence the temperature response of the bottom waters on the western Black Sea shelf.

\section{Discussion}

In his study of the variability of sea surface temperature (SST) in the North Atlantic, Bjerknes (1964) suggested that SST variations on inter-annual timescale may solely be explained by a local forcing from the atmosphere. On the other hand, the explanation of inter-decadal temperature variations requires additional contribution from ocean dynamics, i.e. lateral exchanges (Eden and Willebrand, 2001). The Black Sea is much smaller than the North Atlantic, has a well developed basin- and sub-basin scale circulation pattern (Shapiro, 2008; Altman and Simonov, 1991; Özsoy and Ünlüata, 1997), so that one can expect that temperature reaction to lateral exchanges can be felt faster and be seen in interannual temperature variability. In earlier studies by Buesseler et al. (1991) and Özsoy and Ünlüata (1997) it was suggested that such lateral processes may play an essential role in the ventilation of the pycnocline. Temperature of surface waters responds fairly quickly (on a daily to weekly time scale) to the changes in the meteorological forcing (Stanev et 


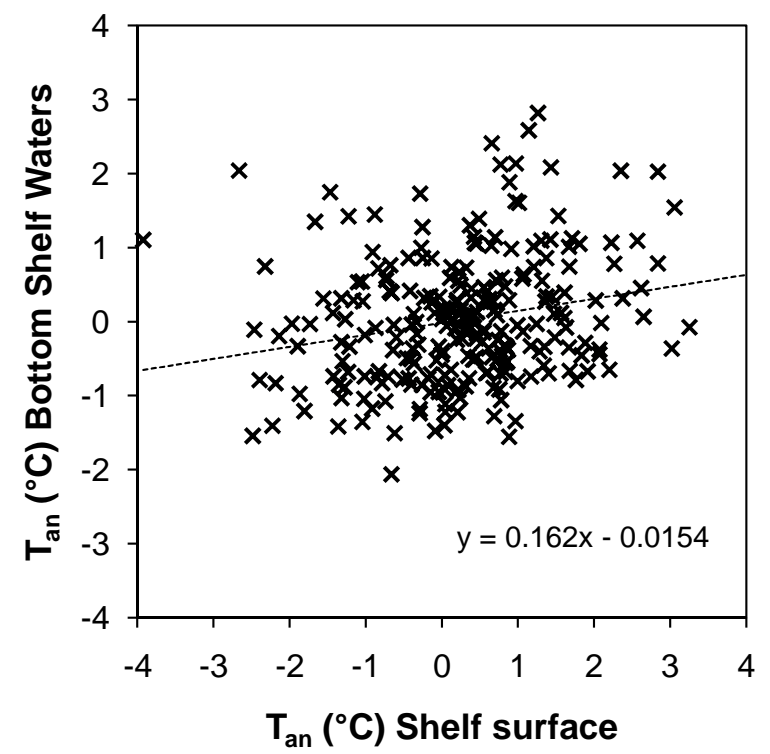

Fig. 11. Correlation between monthly temperature anomalies (1950-2004) in the shelf surface layer (0-10 m) and the BSW during the warm period (May-November).

al., 1995; Enriquez et al., 2005; Schrum et al., 2001). However the waters below the pycnocline on the outer shelf experience only indirect influence from the atmosphere, and hence have greater inertia, so that time scales for local atmospheric forcing and lateral exchanges due to ocean dynamics could become comparable (Ivanov et al., 2000). In this section we contrast and compare vertical and "horizontal" (isopycnic) communications of the bottom waters on the western Black Sea shelf.

The Bottom Shelf Waters (BSW) are defined here as a near-bottom water mass which is located below the upper mixed layer down to the seabed. We use the density level $\sigma_{\theta}=14.2 \mathrm{~kg} \mathrm{~m}^{-3}$ as the lower boundary of the upper mixed layer following previous studies (e.g. Özsoy and Ünlüata, 1997; Ivanov et al., 1997, 2000, 2001). Our calculations (Fig. 11) show that the near-bottom waters on the western Black Sea shelf below this density level remain largely "locked" i.e. isolated from the effects of surface processes from May to November.

The shelf bottom area covered by the "locked" bottom waters is at its smallest at the height of the winter convection period, when a well-mixed water column prevails over large parts of the shelf. As surface heating increasingly stratifies the water column in spring and summer, the "locked" shelf bottom areas reach their maximum extent during JuneAugust, when nearly half the shelf bottom is occupied by BSW.

Vertical mixing is suppressed by intense stratification during the summer. If only diapycnal (vertical) movement is considered the BSW remains mainly locked until at least the following winter. However, the BSW can, in principle, move

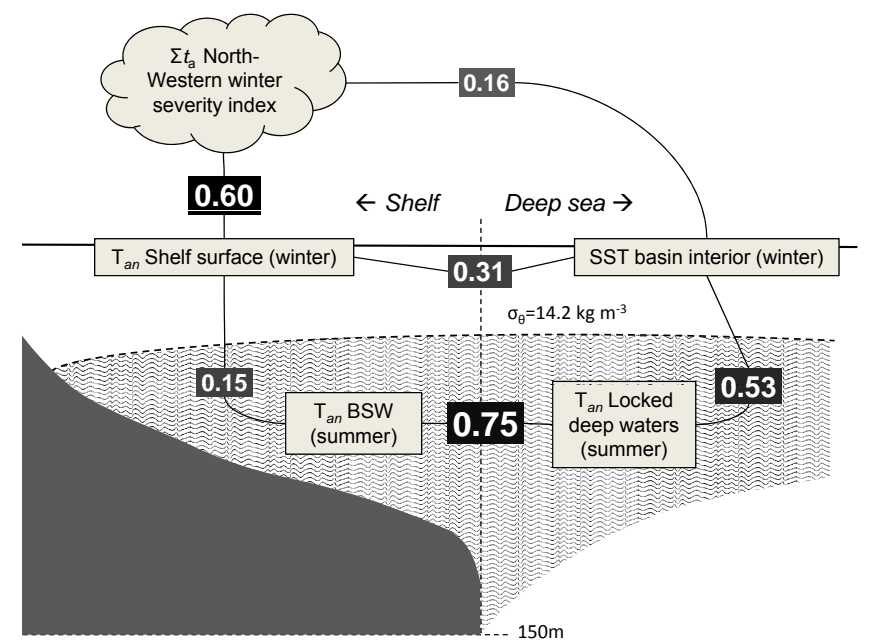

Fig. 12. Schematic of the Pearson correlation (R-values) between various long-term temperature time series over the period 19502005. The shelf limit is the $150 \mathrm{~m}$ isobath, the locked BSW is bounded by the $\sigma_{\theta}=14.2 \mathrm{~kg} \mathrm{~m}^{-3}$ isopycnal and the seabed.

"horizontally", predominantly along the constant density levels and get ventilated via isopycnal exchanges. Density surfaces in the Black Sea are dome-shaped (e.g. Özsoy and Ünlüata, 1997), so that the movements along sloping isopycnals towards the deep sea could bring the BSW upward. As a result, the BSW may in principle re-enter the euphotic zone over the deep sea where they could be biogeochemically reventilated. However, our isopycnic analysis shows that the $\sigma_{\theta}=14.2 \mathrm{~kg} \mathrm{~m}^{-3}$ isopycnal reaches the sea surface only in March-April (see white areas in Fig. 3, left panel as an example), and hence surfacing of BSW due to such mechanism can only happen in early spring. Later in the warm season a strong pycnocline prevents the $\sigma_{\theta}=14.2 \mathrm{~kg} \mathrm{~m}^{-3}$ isopycnal from approaching the surface even in the deep sea.

Not surprisingly, our calculations (see Fig. 12) reveal a strong influence of atmospheric conditions on the shelf surface temperature during the winter season. There is a fairly high correlation, $R=0.60$, between the winter severity in$\operatorname{dex} \Sigma t_{\mathrm{a}}$ and the winter SST on the western Black Sea shelf. The time series of winter SST on the shelf is indicative of the temperature response of the entire shelf water body because the shelf is well-mixed during the winter (e.g. Sorokin, 2002). The effects of atmospheric processes therefore penetrate down to the benthic ecosystem during the cold season.

A high correlation $(R=0.75)$ is shown in Fig. 12 between the temperature anomalies of the BSW and CIW in the adjacent deep sea. With the inception of the warm season and formation of the pycnocline, the influence of the weather on the bottom shelf waters is much reduced, creating a potential for the bottom shelf waters to preserve the memory of the winter conditions in the subsequent months. However the correlation coefficient between winter SST on the shelf and summer temperatures in the BSW is as low as $R=0.15$, 
showing that in reality the memory of the winter conditions is not well preserved in the bottom waters. The situation is quite different in the deep sea, where the winter SST is correlated with the summer temperatures of CIW at a moderate value of $R=0.53$, revealing that the waters within the CIL keep a longer memory of the preceding winter.

Our analysis revises the findings by Ivanov et al. (2000), that traces of winter mixing events appear well preserved in the temperature-salinity structure, are only valid for the deep sea but not on the shelf. The different response of shelf waters can be attributed to their much smaller volume compared to the CIW in the deep sea. Furthermore the upper mixed layer is thinner in the deep sea compared to the shelf as a result of the doming of isopycnal surfaces (e.g. Özsoy and Ünlüata, 1997). It should be noted that the surface waters of the shelf and the deep sea regions appear to be in some communication giving an R-value of 0.31 . The correlation between the winter severity index, which is calculated using data from the costal stations, and the winter SST in the deep sea is very low $(R=0.16)$, confirming the previously reported de-coupling between surface waters of shelf and deep sea regions to climate variations (Shapiro et al., 2010a).

The low vertical and higher lateral correlations of the shelf bottom waters in the summer suggest that the horizontal exchanges below the pycnocline across the shelf break are thus more significant than diapycnic mixing across the pycnocline. Horizontal processes thus appear to account for a substantial degree of inter-annual variability. These exchanges are thought to reduce the memory of winter mixing events on the shelf, while the CIW in the deep sea (which has a much larger volume and higher latency) buffers the traces of winter convection for longer, as observed by Ivanov et al. (2000).

The existence of horizontal exchanges has been suggested in a number of previous studies based on measurements from individual field campaigns. The mainly advective nature of CIW replenishment was probably first proposed by Kolesnikov (1953) and later by Filippov (1965, 1968), however this view was challenged by other researchers (see e.g. Özsoy and Ünlüata, 1997; Zatsepin et al., 2003 for details). Blatov et al. (1984) introduced the concept of cold-water lenses which facilitate horizontal advection along isopycnal surfaces in the CIL. The exposure of the shelf break region to mesoscale circulation is well-established and shelf edge exchange processes can be driven by a number of mechanisms: meandering of the main Rim Current, formation of cross-shelf jets and filaments, transport by mesoscale eddies, dense water cascades, coastal upwelling events etc. (Stanev et al., 2004; Ginzburg et al., 2002; Oğuz et al., 2002; Zatsepin et al., 2003; Gawarkiewicz et al., 1999).

More recently, significant horizontal exchanges across the shelf break in the Black Sea by a mesoscale eddy have been quantified using satellite imagery to show that about $40 \%$ of the shelf waters was exchanged during the period from May to August 2005 (Shapiro et al., 2010b). The depth of penetration of a cross-shelf current induced by a mesoscale eddy can exceed $100 \mathrm{~m}$ and hence such eddies can be influential in maintaining a good correlation between summer temperatures below the $\sigma_{\theta}=14.2$ isopycnal (Korotaev et al., 2006; Aleinik et al., 2007). Complex vertical and horizontal interactions of the BSW result in the inter-annual variability of the near-bottom temperature which mimics exactly neither the winter severity pattern nor the variations in the surface.

The inter-seasonal and inter-decadal variability of temperature in the Bottom Shelf Waters for the period 1950-2004 does not have a simple linear trend; instead it has an oscillating shape shown in Fig. 7. The range of inter-annual variations is as high as $2.9^{\circ} \mathrm{C}$ and it significantly exceeds the range of intra-seasonal variations of $0.7^{\circ} \mathrm{C}$. Shokurova et al. (2004) calculated time series of temperature at a number of depth levels between 50 and $100 \mathrm{~m}$ for August for the period 1951 to 1995 by averaging observed temperatures over the whole Black Sea and aggregating it into 10-yr temporal bins for reducing statistical noise. From data shown in their Fig. 3b one could infer inter-decadal oscillations of temperature averaged within the layer 50-100 m: cold 1950-1970, warm 1970-1980 and cold 1980-1995. Whilst most observations used in Shokurova et al. (2004) were taken in the deep sea, and only data for August were processed, these oscillations loosely coincide with what is seen from our Fig. 7 for the BSW. This is not a surprise as we have shown that temperature variations in the BSW are well correlated with the deep sea due to enhanced horizontal exchanges.

The cold periods seen in the non-smoothed oscillations with a $2 \mathrm{yr}$ period indicate events of increased winter convection in agreement with Ivanov et al. (2000). It is thought that these events would also increase the oxygenation of the BSW, however we do not have sufficient chemical data to support this statistically. The 5-yr running average in Fig. 7 suggests a cyclical oscillation with a period of approx. $20 \mathrm{yr}$ and an amplitude of $\sim 2{ }^{\circ} \mathrm{C}$. A similar periodicity was observed by Ivanov et al. (2000) in a temperature time series of various isohaline surfaces in the deep Black Sea, although the timing of the cooling phases does not coincide exactly. The BSW temperature is characterised by a cooler period in the $1950 \mathrm{~s}$, which was followed by a warm period in the 1960s and 1970s followed by colder-than-usual conditions in 1980-2001 (see Fig. 7). The warmer-than-usual period of 1970-1980s coincided with the timing of significant eutrophication, whilst during the cold period the signs of the regime shift in the state of the ecosystem and some ecosystem recovery have been observed (Mee et al., 2005). The 1990s belong to the colder-than-usual period; however the start of a warming tendency is evident from mid-1990s. There is no guarantee that future variations in the BSW temperature will repeat the oscillatory pattern of the past, but if they did we would have expected the current trend to have brought the BSW temperatures into the warmer-than-usual zone by about 2004 and the warming phase to last until approximately 2015. 


\section{Conclusions}

The Bottom Shelf Water (BSW) is defined as located between the density surface $\sigma_{\theta}=14.2 \mathrm{~kg} \mathrm{~m}^{-3}$ and the seabed on the western Black Sea shelf where the bathymetric depth less than $150 \mathrm{~m}$. During the warm season from May to November it is isolated from exchanges with the surface layer and hence has a limited supply of oxygen due to a lack in diapycnic mixing. The area occupied by the "locked" bottom waters reaches $45 \%$ of the total shelf area during the summer months.

The use of anomalies rather than absolute temperature values allows aggregating the data spatially and reducing statistical uncertainties. The novelty of our result is that we now are able to show inter-annual/inter-decadal variability of the Bottom Shelf Water temperatures and quantify the relative importance of horizontal (isopycnal) communications as compared to vertical mixing based on a very large data base spanning over more than $50 \mathrm{yr}$.

There is little intra-seasonal (i.e. month-to-month) variation of the temperature of the BSW during May-November. To the contrary, the inter-annual variability is significant. The time line of the BSW temperature shows a warm phase (1960s-1980s) and a cold phase (1980s-2000s). Whilst the warm phase coincides with environmental deterioration, the colder-than-usual period coincides with signs of recovery of the Black Sea ecosystem.

The correlation analysis suggests that over the summer months the BSW generally loses memory of winter-time atmospheric forcing on the shelf, while traces of local winter cooling are reasonably well preserved in the deep sea. Lateral exchanges of the BSW with the Cold Intermediate Waters (CIW) from the deep sea are shown to be more important for controlling inter-annual temperature variations of the BSW than winter conditions on the shelf itself.

Acknowledgements. This study was partially supported by the following grants: EU FP6 SESAME, EU FP7 MyOcean, EU FP7 HYPOX Grant 226213, RFBR-07-05-00240 and the NATO Environmental Security Grant ESP.NUCR.CLG.982285.

Edited by: E. J. M. Delhez

\section{References}

Aleinik, D. D., Shapiro, G. I., Mee, L. D., and Lemeshko, E. M.: Using a lowered acoustic Doppler current profiler for measuring current velocities in the Black Sea, Oceanology, 47, 127-134, 2007.

Altman, E. N. and Simonov, A. I. (Eds.): Hydrometeorology and hydrochemistry of USSR seas, vol. 4, The Black Sea, Gidrometeoizdat, St. Petersburg, 428 pp., 1991.

Belokopytov, V. N.: Long-term variability of cold intermediate layer renewal conditions in the Black Sea, in: Ecosystem Modeling as a Management Tool for the Black Sea, NATO Science Series, 2. Environmental Security -47 . Vol. 2, edited by: Ivanov,
L. I. and Oğuz, T., 2, Kluwer Academic Publishers, Dordrecht, NL, 47-52, 1998.

Bjerknes, J.: Atlantic air-sea interaction, in: Advances in Geophysics, vol. 10, edited by: Landberg, H. E. and van Mieghem, J., Academic Press, New York, 1-82, 1964.

Blatov, A. S., Bulgakov, N. P., Ivanov, V. A., Kosarev, A. N., and Tuzhilkin, V. S.: Variability of Hydrophysical Fields of the Black Sea Gidrometeoizdat, Leningrad, 240 pp., 1984.

Boyer, T., Levitus, S., Antonov, J., Locarnini, R., Mishonov, A., Garcia, H., and Josey, S. A.: Changes in freshwater content in the North Atlantic Ocean 1955-2006, Geophys. Res. Lett., 34, 16603, doi:10.1029/2007GL030126, 2007.

Boyer, T. P., Levitus, S., Antonov, J. I., Locarnini, R. A., and Garcia, H. E.: Linear trends in salinity for the World Ocean, 1955-1998, Geophys. Res. Lett., 32, 1-4, 2005.

Buesseler, K. O., Livingston, H. D., and Casso, S. A.: Mixing between oxic and anoxic waters of the Black Sea as traced by Chernobyl cesium isotopes, Deep-Sea Res., 38, S725-S745, 1991.

Daskalov, G. M.: Long-term changes in fish abundance and environmental indices in the Black Sea, Mar. Ecol.-Prog. Ser., 255, 259-270, 2003.

Eden, C. and Willebrand, J.: Mechanism of Interannual to Decadal Variability of the North Atlantic Circulation, J. Climate, 14, 2266-2280, 2001.

Enriquez, C. E., Shapiro, G. I., Souza, A. J., and Zatsepin, A. G.: Hydrodynamic modelling of mesoscale eddies in the Black Sea, Ocean Dynam., 55, 476-489, 2005.

Filippov, D. M.: The cold intermediate layer in the Black Sea, Oceanology, 5, 47-52, 1965.

Filippov, D. M.: Tsirkulyatsiya i structure vod Chernogo morya (Circulation and Structure of the Black Sea Water), Nauka, Moscow, 136 pp., 1968.

Gawarkiewicz, G., Korotaev, G., Stanichny, S. V., Repetin, L., and Soloviev, D.: Synoptic upwelling and cross-shelf transport processes along the Crimean coast of the Black Sea, Cont. Shelf Res., 19, 977-1005, 1999.

Ginzburg, A. I., Kostianoy, A. G., Krivosheya, V. G., Nezlin, N. P., Soloviev, D. M., Stanichny, S. V., and Yakubenko, V. G.: Mesoscale eddies and related processes in the northeastern Black Sea, J. Marine Syst., 32, 71-90, 2002.

Hansen, J. and Lebedeff, S.: Global trends of measured surface air temperature, J. Geophys. Res., 92, 345-372, 1987.

Ivanov, L. I., Beşiktepe, Ş. T. and Özsoy, E.: The Black Sea Cold Intermediate Layer, in: Sensitivity to Change: Black Sea, Baltic Sea and North Sea, edited by: Özsoy, E. and Mikaelyan, A., Kluwer Academic Publishers, Dordrecht, NL, 253-264, 1997.

Ivanov, L. I., Belokopytov, V. N., Özsoy, E., and Samodurov, A.: Ventilation of the Black Sea pycnocline on seasonal and interannual time scales, Mediterr. Mar. Sci., 1/2, 61-74, 2000.

Ivanov, L. I., Backhaus, J. O., Özsoy, E., and Wehde, H.: Convection in the Black Sea during cold winters, J. Marine Syst., 31, 65-76, 2001.

Jones, P. and Mann, M. E.: Climate over past millennia, Rev. Geophys., 42, 1-42, 2004.

Keondzhyan, V. P., Kudin, A. M., and Terekhin, Y. V. (Eds.): Prakticheskaya ekologiya morskikh regionov. Chernoe more (Practical Ecology of Marine Regions. Black Sea), Naukova Dumka, Kiev, 252 pp., 1990.

Kolesnikov, A.: Seasonal course of temperature, stability and 
vertical turbulent heat exchange in the open part of the Black Sea, Tr. Mor. Gudrol. Inst. USSR AS, 3, 3-13, 1953.

Korotaev, G., Oğuz, T., and Riser, S.: Intermediate and deep currents of the Black Sea obtained from autonomous profiling floats, Deep-Sea Res. Pt. II, 53, 1901-1910, 2006.

Levitus, S., Antonov, J., Boyer, T., Locarnini, R., Garcia, H., and Mishonov, A.: Global ocean heat content 1955-2008 in light of recently revealed instrumentation problems, Geophys. Res. Lett., 36, L07608, doi:10.1029/2008GL037155, 2009.

Lozier, M. S., Owens, W. B., and Curry, R. G.: The climatology of the North Atlantic, Prog. Oceanogr., 36, 1-44, 1995.

McQuatters-Gollop, A., Mee, L. D., Raitsos, D. E., and Shapiro, G. I.: Non-linearities, regime shifts and recovery: The recent influence of climate on Black Sea chlorophyll, J. Marine Syst., 74, 649-658, 2008.

Mee, L. D., Friedrich, J., and Gomoiu, M. T.: Restoring the Black Sea in times of uncertainty, Oceanography, 18, 32-43, 2005.

Murray, J. W., Codispoti, L. A., and Friederich, G. E.: Oxidationreduction environments. The suboxic zone in the Black Sea, in: Aquatic Chemistry: Interfacial and Interspecies Processes, ACS Advances in Chemistry Series, vol. 244, edited by: Huang, C.P., O’Melia, C. R., and Morgan, J. J., Advances in Chemistry, American Chemical Society, Washington, DC, 157-176, 1995.

NGDC: ETOPO2v2 Global Gridded 2-minute Database, National Geophysical Data Center, National Oceanic and Atmospheric Administration: http://www.ngdc.noaa.gov/mgg/global/etopo2. html, 2006.

Oğuz, T.: Black Sea ecosystem response to climatic teleconnections, Oceanography, 18, 122-133, 2005.

Oğuz, T., Malanotte-Rizzoli, P., Ducklow, H. W., and Murray, J. W.: Interdisciplinary studies integrating the Black Sea biogeochemistry and circulation dynamics, Oceanography, 15, 4-11, 2002.

Oğuz, T., Dippner, J. W., and Kaymaz, Z.: Climatic regulation of the Black Sea hydro-meteorological and ecological properties at interannual-to-decadal time scales, J. Marine Syst., 60, 235-254, 2006.

Özsoy, E. and Ünlüata, Ü.: Oceanography of the Black Sea: a review of some recent results, Earth-Sci. Rev., 42, 231-272, 1997.

Salihoglu, I.: Black Sea Integrated Coastal and Shelf Zone Monitoring and Modeling (INCOM) Program Science Plan, Report No. 248, NATO Committee on the Challenges of Modern Society (CCMS), 49 pp., 2000.

Schrum, C., Staneva, J., Stanev, E., and Özsoy, E.: Air-sea exchange in the Black Sea estimated from atmospheric analysis for the period 1979-1993, J. Marine Syst., 31, 3-19, 2001.

Shapiro, G. I.: Black Sea Circulation, in: Encyclopedia of Ocean Sciences, 2nd edn., edited by: Steele, J. H., Turekian, K. K., and Thorpe, S. A., Academic Press, Oxford, 3519-3532, 2008.

Shapiro, G. I., Aleynik, D. L., and Mee, L. D.: Long term trends in the sea surface temperature of the Black Sea, Ocean Sci., 6, 491-501, doi:10.5194/os-6-491-2010, 2010a.

Shapiro, G. I., Stanichny, S. V., and Stanychna, R. R.: Anatomy of shelf-deep sea exchanges by a mesoscale eddy in the North West Black Sea as derived from remotely sensed data, Remote Sens. Environ., 114, 867-875, 2010b.
Shokurova, I. G., Plastun, T. V., Belokopytov, V. N., and Khaliulin, A. K.: Comparative analysis of variability of hydrological parameters of water in the northwest and central Black Sea, Ecological safety of coastal and shelf zone and complex use of their resources: Proceedings, 17-26, 2004.

Sorokin, Y. I.: The Black Sea: Ecology and Oceanography, Backhuys Publishers, Leiden, NL, 875 pp., 2002.

Stanev, E. V., Roussenov, V. M., Rachev, N. H., and Staneva, J. V.: Sea response to atmospheric variability. Model study for the Black Sea, J. Marine Syst., 6, 241-267, 1995.

Stanev, E. V., Staneva, J. V., Bullister, J. L., and Murray, J. W.: Ventilation of the Black Sea pycnocline. Parameterization of convection, numerical simulations and validations against observed chlorofluorocarbon data, Deep-Sea Res. Pt. I, 51, 2137-2169, 2004.

Stephens, C., Antonov, J. I., Boyer, T. P., Conkright, M. E., Locarnini, R. A., O'Brien, T. D., and Garcia, H. E.: World Ocean Atlas 2001 vol. 1: Temperature, in: NOAA Atlas NESDIS 49, edited by: Levitus, S., US Government Printing Office, Washington, DC, 2002.

Sur, H. İ., Özsoy, E., Ilyin, Y. P., and Ünlüata, Ü.: Coastal/deep ocean interactions in the Black Sea and their ecological/environmental impacts, J. Marine Syst., 7, 293-320, 1996.

Suvorov, A. M., Eremeev, V. N., Belokopytov, V. N., Khaliulin, A. H., Godin, E. A., Ingerov, A. V., Palmer, D. R., and Levitus, S.: Digital atlas: Physical oceanography of the Black Sea, in: Environmental Control Systems, edited by: Eremeev, V. N., National Academy of Science of Ukraine, Sevastopol, 125-129, 2004.

Vinogradov, M. E. and Nalbandov, Y. R.: Effect of changes in water density on the profiles of physicochemical and biological characteristics in the pelagic ecosystem of the Black Sea, Oceanology, 30, 567-573, 1990.

Willis, J. K., Roemmich, D., and Cornuelle, B.: Interannual variability in upper ocean heat content, temperature, and thermosteric expansion on global scales, J. Geophys. Res., 109, C12036, doi:10.1029/2003JC002260, 2004.

Yakushev, E., Podymov, O., and Chasovnikov, V.: Seasonal Changes in Hydrochemical Structure of the Black Sea Redox Zone, Oceanography, 18, 44-51, 2005.

Zaitsev, Y. P.: Ecological consequences of anoxic events at the north-western Black Sea Shelf, in: Past and Present Water Column Anoxia. NATO Science Series, IV. Earth and Environmental Sciences, edited by: Neretin, L. N., 247-256, 2006.

Zaitsev, Y. P., Alexandrov, B. G., Berlinsky, N. A., and Zenetos, A.: Europe's biodiversity - biogeographical regions and seas: The Black Sea an oxygen-poor sea, EEA (European Environment Agency), Copenhagen, 2002.

Zatsepin, A. G., Ginzburg, A. I., Kostianoy, A. G., Kremenetskiy, V. V., Krivosheya, V. G., Stanichny, S. V., and Poulain, P.-M.: Observations of Black Sea mesoscale eddies and associated horizontal mixing, J. Geophys. Res. Oceans, 108, 3246-3274, 2003. 